other compounds could reduce overeating without inducing nausea.

J. Neurosci. 33, 18368-18380 (2013)

\section{VIROLOGY}

\section{A more predictable flu}

Influenza viruses may have fewer routes for escaping vaccines than previously thought.

Flu vaccines target a viral protein called haemagglutinin, which mutates frequently, rendering vaccines ineffective. Derek Smith of the University of Cambridge, UK, and Ron Fouchier of Erasmus Medical Center in Rotterdam, the Netherlands, and their colleagues studied how the haemagglutinin protein has mutated to evade vaccines - a process called antigenic drift - over a 35-year period from 1968 to 2003.

They found that seven of the ten antigenic drift events in the past three decades were caused by a change in just one amino acid in the protein. These changes occurred at only seven places in the protein, all of which cluster near a region that binds to host cells. The results could one day lead to moreeffective flu vaccines.

Science 342, 976-979 (2013)

\section{ECOLOGY}

\section{Mother frogs arm their tadpoles}

Some animals make chemical defences against predators; others obtain them from their food. Researchers have now found the first example of parents chemically arming their young after birth.

Ralph Saporito of John Carroll University in University Heights, Ohio, and his colleagues analysed specimens of the strawberry poison frog Oophaga pumilio (pictured) from all stages of the life cycle. Newly hatched tadpoles had no defensive alkaloids, but after their mothers began producing unfertilized 'nutritive eggs' for them to eat, tadpole alkaloid concentrations rose. Adult frogs obtain the alkaloids from ants and mites in their diet.

Hand-reared O. pumilio that were fed nutritive eggs from another frog species lacking chemical defences remained alkaloid-free.

Ecology http://doi.org/p59 (2013)

Smells maintain
blood cells

Fruitfly larvae need to sense odours to maintain a pool of the cells that give rise to blood cells.

A team led by Utpal Banerjee at the University of California, Los Angeles, studied mutants of Drosophila melanogaster to identify molecular signals connecting odour sensing to blood progenitor cells. They found that smells prevent the cells from specializing, or differentiating, before they are required.

When the team activated olfactory neurons in the fly's brain, the neurons secreted a chemical called GABA into the blood, triggering blood progenitors to let in calcium ions. Calcium maintains the cells as undifferentiated progenitors. Larvae raised in environments with few odours had low levels of GABA, and their blood progenitor cells differentiated earlier.

Whether similar links exist between sensory perception and progenitor cells in more complex organisms is not clear. Cell 155, 1141-1153 (2013)

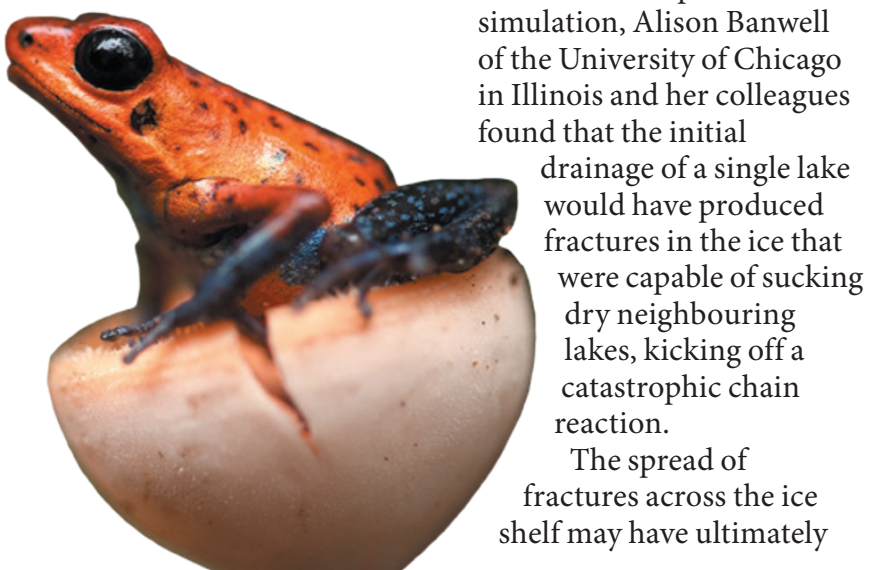

HIGHLY READ
on iopscience.
iop.org
20 Oct-19 Nov
in saltier water. New J. Phys. 15, 103012 (2013)

\section{GLACIOLOGY}

\section{Anatomy of an ice shelf's demise}

The sudden drainage of thousands of small lakes on the surface of Antarctic glaciers seems to have triggered the spectacular collapse of the Larsen B ice shelf in March 2012.

Some 3,000 small ponds of liquid water had emerged over the course of a decade on top of glaciers surrounding the ice shelf on the Antarctic Peninsula. These ponds disappeared in striking synchronicity a few days before the shelf's collapse.

When recreating the events in a computer simulation, Alison Banwell of the University of Chicago in Illinois and her colleagues drainage of a single lake would have produced fractures in the ice that of sucking dry neighbouring lakes, kicking off a catastrophic chain eaction.

fractures across the ice shelf may have ultimately

The most viewed papers in science

PHYSICS

\title{
Pinch of salt makes for bumpy icicles
}

Impurities in water are behind the ripples seen around an icicle's circumference.

Ripples or ribs form naturally in icicles, an effect that previous theories attributed to surface tension in the thin film of water that flows over the ice. Antony Szu-Han Chen and Stephen Morris at the University of Toronto, Canada, analysed 67 icicles grown under a broad range of conditions in the laboratory. They found that whereas icicles made from pure water were ripple-free, even small amounts of salt dissolved in the water - less than is found in most tap water - caused ripples to emerge. The ribs also grew faster

Existing theories do not account for the effects of impurities in ripple formation, leaving salt's role in the process a mystery.

caused its sudden demise, the authors suggest.

Geophys. Res. Lett. http://doi. org/p6c (2013)

\section{ORGANIC CHEMISTRY}

\section{Fast and easy fluorine fix}

Many drug compounds and agrochemicals are fluorinated, but adding fluorine atoms to organic molecules can be dangerous and expensive. Patrick Fier and John Hartwig at the University of California, Berkeley, report a way to fluorinate one class of molecules at room temperature and without the need for harsh reagents.

They showed that silver(II) fluoride can swap a hydrogen atom for a fluorine atom on molecules containing nitrogen as part of a ring of carbon atoms. The reaction replaces only the hydrogen attached to carbons next to the nitrogen in the ring. It occurs quickly and uses only commercially available reagents.

Science 342, 956-960 (2013)

\section{NATURE.COM}

For the latest research published by Naturevisit:

www.nature.com/latestresearch 